\title{
Human Immunodeficiency Virus and the Central Nervous System
}

\section{Sergio Monteiro de Almeida ${ }^{1,2}$, Scott Letendre ${ }^{2}$ and Ron Ellis ${ }^{2}$}

\author{
${ }^{I}$ Neurology Unit, Universidade Federal do Paraná; Curitiba, PR, Brazil; \\ ${ }^{2}$ HIV Neurobehavioral Research Center, UCSD, San Diego, CA, USA
}

\begin{abstract}
The pandemic of HIV/AIDS continues to grow daily. Incident cases among women, intravenous drug users and ethnic minorities comprise the fastest growing segment of the HIV-infected population, and the number of $\mathrm{HIV}$-infected individuals over the age of $\mathbf{5 0}$ is growing rapidly. Today, the central nervous system and the immune system are seen as main targets of HIV infection. Significant progress in the knowledge and treatment of AIDS has been obtained in recent years. The neurological manifestations directly related to HIV are acute viral meningitis, chronic meningitis, $\mathrm{HIV}$-associated dementia (HAD), vacuolar myelopathy, and involvement of the peripheral nervous system.

Key Words: HIV, AIDS, HIV dementia, central nervous system, cerebrospinal fluid, viral load, chemokines.
\end{abstract}

Since the recognition of AIDS in 1981, HIV has become a worldwide epidemic. This, the last pandemic of the $20^{\text {th }}$ century, continues to grow rapidly. Worldwide there are about 18,000 newly-infected people per day [1,2], with approximately 40 million infected worldwide (AIDS epidemic update, UNAIDS, December, 2003). In the United States, nearly one million people are infected with HIV. Incident cases among women, intravenous drug users and ethnic minorities comprise the fastest growing segment of the HIV-infected population, and the number of HIV-infected individuals over the age of 50 is growing rapidly.

After the widespread use of a new treatment regimen, Highly Active Antiretroviral Therapy (HAART), a significant decrease in the number of the opportunistic infections and an increase in patients' life expectancy were observed [3].

During the course of infection, HIV replicates, actively producing around 10 virions that are genetically different and are related to immunological escape, higher pathogenicity, drug resistance and predisposition to infect the CNS [4,5].

In tropical areas, the common opportunist infections are associated with specific regional illnesses, resulting in a different picture of the epidemic when compared with the United States or Europe. Examples of this are the high incidence of tuberculosis [6] schistosomiasis, trypanosomiasis [7-18] and some cases of paracoccidioidomycosis $[19,20]$ in the CNS.

Ten percent of patients that are diagnosed with AIDS also have some neurological complaint, $40 \%$ present neurological signs or symptoms during the course of the infection, and $80 \%$ of the autopsies present neurological alterations [21,22]. Although much is known about the neuropathology of HIV infection, many important questions on its neuropathogenesis remain unanswered [23].

Received on 11 September 2005; revised 07 January 2006.

Address for correspondence:Dr.Sergio Monteiro de Almeida, MD, PhD. 150 West Washington St. 2nd FLR, San Diego, CA 92103, USA. Phone: 1619 5436241. FAX 1801681 8514. E-mail: sdealmeida@ucsd.edu

The Brazilian Journal of Infectious Diseases 2006;10(1):41-50. (C) 2006 by The Brazilian Journal of Infectious Diseases and Contexto Publishing. All rights reserved.

\section{Neurological Complications Related to HIV}

Initial neurological interest in HIV infection was focused on opportunist infections and tumors that affect the CNS. At the time, the CNS was considered to only be indirectly involved in the progression of HIV disease [24,25]. Today we know that the CNS and the immune system are major targets of HIV infection $[24,26]$. HIV has been isolated from CNS tissue and intrathecal synthesis of anti-HIV antibodies have been found in patients with AIDS and neurological illness [27,28]. In the adult brain, only macrophages and microglia are productively infected, and HIV does not effectively enter or replicate in neurons, suggesting that dementia occurs by indirect mechanisms.

There exist more morphological similarities between the genome of HIV and that of visna virus, a retrovirus from the Lentivirinae subfamily that also includes HIV, than with the retroviruses HTLV-I and HTLV-II, which are oncoviruses. This observation led to the alteration of the classification and nomination of HIV, which until then was called HTLV-III. Visna virus is responsible for sheep encephalopathy, and like all lentiviruses, it has a predisposition to infect macrophages and tropism to the CNS [29]. Taken together, these findings suggest primary infection of HIV in the CNS.

The neurological manifestations directly related to HIV are acute viral meningitis, chronic meningitis, dementia associated with HIV, vacuolar myelopathy and involvement of the peripheral nervous system. There is a direct relationship between the neurological complications, the phase of HIV infection, and the level of immunological involvement. Moreover it can occur simultaneously on multiple levels of the neuroaxis and can facilitate the coexistence of multiple complications $[24,25,30]$.

\section{When Does HIV Penetrate into the CNS?}

It is possible that HIV penetrates the CNS in an initial phase of the infection. During this period, the viral load in the peripheral blood is as high as it is in the terminal phase of the illness [28,31]. Some researchers have identified HIV proteins 
[27] or intrathecal synthesis of anti-HIV antibodies, in the initial phase of infection [28].

Around 5 to $10 \%$ of patients present acute viral meningitis, at the time that the virus is acquired or during the seroconversion phase. This acute meningitis does not differ from the point of view of the cytological or biochemical characteristics of the cerebral-spinal fluid (CSF), nor does it differ clinically from acute meningitis acquired through other viruses, such as enteroviruses. Some patients, however, do have peripheral facial palsy associated with the meningitis [32]. As the seroconversion proceeds in this phase of acute meningitis, the search for antiHIV antibodies in serum or CSF is negative [33-35].

\section{Penetration of HIV-1 into the CNS}

The penetration of HIV into the CNS through neurons by axonal flow, as occurs with herpes virus and rabies virus, is less probable because the $\mathrm{CD} 4$ receptor, the main receptor that enables HIV to infect the cell, is absent on neurons [26]. A more likely possibility is penetration through a hematogenic pathway. This occurs through free particles in the CNS crossing the microvessels that compose the blood brain barrier (BBB) or the blood CSF barrier (BCB), or through infected cells, such as lymphocytes or monocytes. Possibly all of these forms of penetration are involved, acquiring greater or lesser importance depending on the phase of the infection [36]. The penetration through infected monocytes/macrophages, the "Trojan Horse" theory, is currently considered to be the main form of HIV entrance into the CNS [35,37].

The disrupted BBB during HIV infection allows free particles and infected monocytes to penetrate into the CNS. These cells can enter through tight junctions or through the endothelial cells of the capillaries, with the latter being more likely than the former. In addition to this, higher levels of matrix metalloproteinases (MMPs) in the CNS have been found. MMPs can weaken the basal membrane, facilitating the migration of leukocytes across the BBB [38,39]. HIV-1 infected monocytes show an increase in adhesion in endothelial and astrocyte cell cultures. Endothelial cells with modified function can increase endothelial adhesion and the infiltration of the infected monocytes in the CNS, due to alterations of the composition of proteins of the basal membrane. These alterations are at the same time due to production of derivatives of the virus proper or of free chemokines, by either infected cells, non-infected cells or by the infection of astrocytes. It has been shown that HIV Tat protein activates endothelial cells, resulting in an increase of the expression of adhesion molecules, MMPs and cytokines. This results in the CNS serving as an important reservoir of HIV infection [36,40,41].

\section{Potentially HIV-infected CNS Cells}

Two types of CNS cells can be infected by HIV, cells derived from monocytes (microglia and macrophages) and astrocytes. These cells differ from other HIV-infected cells in some biological aspects, particularly in the way they express HIV products. The cellular surface $\mathrm{CD}_{4}$ receptor and the receptors of chemokines CCR5 and CCR3 are involved in the penetration of the virus in the cells of the microglia. The microglia develop a productive infection, leading to syncytial formation and cell death; however, the possibility of chronic infection also exists.

Alternatively, the astrocytes are infected predominantly by lymphotropic strains; however, infections with monocytotropic strains have also been described. Currently, the entrance mechanism of HIV into astrocytes remains unknown. It has been clearly shown that astrocytes do not have $\mathrm{CD}_{4}$ receptors on their surface. The chemokine receptors involved in HIV infection are also not expressed; however, some authors suggest that CXCR 4 can be expressed following the activation of astrocytes [42,43-46].

Another protein, "Pag" (a protein on astrocytes for gp 120 binding), has been related to astrocyte infection. After one short phase of productive viral infection, the HIV-1 present in astrocytes enters in a latent or restrictive phase. The infection of astrocytes is not cytopathic; therefore virus can remain in these cells almost indefinitely. In this phase of the infection, the virus could escape the action of all antiretrovirals currently in use. From time to time following chemokine stimulation, a productive viral response can occur that could, potentially, reinfect the CNS and the peripheral blood [36,47-49].

Chemokines and their receptors have a central role in the interactions between HIV and the host. In the normal host, chemokines regulate immunological functions, such as chemotaxis, cellular activation and the expression of receptors. Chemokine receptors allow HIV to enter and infect susceptible cells, and their deregulation contributes to the immunological loss that occurs in AIDS. Finally, because chemokine receptors are present in neurons and glia, potentially transmitting signals between brain cells, they can either directly or indirectly produce neuronal damage [50-52].

\section{Mechanisms of CNS Injury}

As neurons do not have $\mathrm{CD}_{4}$ cell surface receptors, it is not probable that HIV infects neurons directly. So how do we explain dementia without neuronal involvement? HIV presence in the CNS is necessary, but not adequate enough by itself to develop HIV dementia [53]. More likely, neuronal injury occurs by indirect mechanisms $[24,26,54,55]$ (Table 1 ).

Neurotoxicity is not necessarily induced by long and continuous exposition to viral proteins. Transitory exposition can be enough to start a cascade of events that result in neuronal damage. These viral proteins, once available in the extracellular space, can cause neurotoxicity by direct action on the neuronal cell, or they can activate the glial cells, allowing the viral proteins to amplify their potential neurotoxicity and cause damage at a distance. Moreover, the viral proteins can 
Table1. Indirect mechanisms of neurotoxicity

\begin{tabular}{|c|c|}
\hline Virus proteins & $\begin{array}{l}\text { gp } 120 \\
\text { gp } 41 \\
\text { tat } \\
\text { nef }\end{array}$ \\
\hline Macrophage factors & $\begin{array}{l}\text { toxic factors of low molecular weight } \\
\text { quinolonic acid } \\
\text { metabolites of arcquidonic acid } \\
\text { - prostaglandins } \\
\text { - leucotriens }\end{array}$ \\
\hline Cytokines & $\begin{array}{l}\text { TNF- alfa } \\
\text { IL-1, IL-6, GM-CSF, IFN- }\end{array}$ \\
\hline Chemokines & $\begin{array}{l}\text { MCP-1, MCP-2, MCP-3 } \\
\text { RANTES, MIP-1, MIP-1 }\end{array}$ \\
\hline Neutrophic factors & Neuroleuquins \\
\hline Auto-immunity (mimic) & $\begin{array}{l}\text { gp41 } \\
\text { antiastrocytes antibodies } \\
\text { antibodies anti-brain; }\end{array}$ \\
\hline $\begin{array}{l}\text { antigangliosideos } \\
\text { BBB disruption }\end{array}$ & $\begin{array}{l}\text { neurotoxins from the systemic } \\
\text { infection (?) }\end{array}$ \\
\hline
\end{tabular}

act in synergy with another neurotoxic substance, such as glutamate, to cause neurotoxicity. Acting in this way, sublevels of viral or cellular toxins could summate resulting in neuronal injury $[24,26,54-56]$.

\section{Extracellular Space, Toxin Degradation and Transport}

In general, animal viruses inefficiently incorporate structural proteins into viral particles. Once cytopathic infections initiate the release of viral proteins into the extracellular space, these viral proteins have the chance to interact with non-infected cells and cause cellular dysfunction or toxicity. Studies have shown that the Tat protein is actively released by infected cells; however, not all proteins of HIV-1 have been similarly studied. The distribution of the Tat protein in the extracellular space would be expectedly high due to the close proximity to infected cells [26,57].

Extracellular space in the brain makes up approximately $20 \%$ of the brain volume, and the size of the space changes in accordance with the region. Moreover, the extracellular space is a dynamic space that increases in potassium after neuronal depolarization. It lowers in $\mathrm{pH}$, or the alterations in the sodium concentrations can lead to the reduction in the size of the extracellular space to around $50 \%$ of normal. Factors such as tortuosity and edema of glial cells can also have an impact on the extracellular volume. This is excellent for patients with HIV infection, because the hypertrophy of astrocytes is found to be initially important. The relative neurotoxic substance concentration can increase significantly without any increase in the total amount in the area $[55,57,58]$.

\section{The CNS as a Sanctuary for HIV-1}

The main objective of treatment through a combination of antiretrovirals is to suppress the replication of HIV in all cellular compartments or tissues [59]. The CNS is especially important. The effective treatment of neurocognitive disorders related to HIV is most likely dependent on the complete suppression of the replication of HIV in the CNS. The lack of complete suppression of replication in the CNS, related to factors such as lack of antiretroviral drug penetration into the CNS, can facilitate the development of resistance to antiretroviral drugs or permit mutations in the virus. Both result in situations that enable the virus to re-disperse the infection throughout the CNS tissue. In this context, the CNS has been considered as a possible reservoir or sanctuary for HIV [40,41,60-62].

\section{Viral load of HIV in the LCR}

In the peripheral blood, there is no relationship between viral load and neurological symptoms during primary HIV infection [40]. This is not true however, in the CSF, where higher viral load is related to neurological symptoms. Also, patients without neurological symptoms were found to have a significantly decreased viral load in the CSF, compared to the blood [63].

The clinical importance of the determination of the viral load in the CSF is to monitor the therapeutic effect of HAART, to identify patients with CNS escape, distinguishing diagnosis with psychiatric symptoms [49].

Among patients with $\mathrm{CD}_{4}^{+}>200$ cells $/ \mu \mathrm{L}$, the viral load in the CSF is positively correlated with the viral load in blood, but it is not correlated with neurological alterations. After the institution of HAART, patient viral load decreases in the CSF in parallel with blood levels. Among patients with $\mathrm{CD}_{4}{ }^{+}<200$ cells $/ \mu \mathrm{L}$, the viral load in the CSF correlates with the neurological alterations. However, there is no correlation between the viral load in the CSF and the viral load in the peripheral blood; after HAART there is a slower decrease in CSF viral load in comparison to blood $[64,65]$.

The viral particles in CSF can have different origins. They can drain to the CSF perivascular spaces; they can be produced by infected cells in meninges; and they can cross from the plasma during the production of LCR by the choroid plexus, particularly if there is damage or inflammation of the choroid plexus [66].

\section{HIV Associated with Dementia}

Human immunodeficiency virus-type 1 (HIV-1) infection is the most common preventable and treatable cause of neurocognitive impairment in individuals under age 50. The American Academy of Neurology and the World Health Organization (WHO) $(1991,1996)$ recommend the terms "HIVassociated dementia" and "HIV-1 associated minor cognitive- 
motor complex" to designate the major and minor forms of cognitive impairment in HIV infection [67]. The latter does not involve impairment in daily life activities.

In adults, $3 \%$ of AIDS cases present with dementia as the first defining AIDS illness. More typically, the dementia is initiated through substantial immune deficiency and other defining systemic opportunist complications of AIDS.

Prevalence and risk factors. Early in the HIV epidemic, dementia was a common sequel of advanced disease, affecting more than $50 \%$ of patients prior to death. Subsequently, widespread treatment with zidovudine (AZT) reduced the incidence of HIV dementia dramatically [68]. With the later introduction of combination therapy and PI-based highly active antiretroviral therapies (HAART), further improvement was seen [59,69]. The incidence of most HIV-related opportunistic infections, including those affecting the CNS, dropped markedly. Changes in diagnosis and clinical management altered the face of HIV, such that what was once an almost uniformly fatal illness is now, at least for those in developed countries, where antiretroviral drugs are available, a chronic disease requiring long term medical management. Survival has been greatly prolonged among patients with dementia [70]. More recently, the appearance of dementia in persons whose $\mathrm{CD}_{4}$ counts have rebounded with ART, and the relative increase of dementia as a proportion of AIDSdefining opportunistic illnesses [59,71,72] has suggested to some that the CNS is not being treated as effectively as the lymphatic tissues.

Risk factors for AIDS dementia are older age at diagnosis of AIDS, elevated plasma viral load ( $>50,000$ copies per $\mathrm{mL}$ ), elevated cerebrospinal fluid (CSF) viral load (>200 copies/ $\mathrm{mL}), \mathrm{CD}_{4}$ count less than $100 / \mu \mathrm{L}$; low hemoglobin concentration (less than $15 \mathrm{mg} / \mathrm{dL}$ ), and systemic disease progression.

Neuropathogenesis. HIV encephalitis is a diagnosis made by neuropathological evaluation of brain tissue. It is characterized by a number of features that are individually nonspecific (white matter pallor, microglial nodules, multinucleated giant cells, and gliosis), but when they occur as a constellation in the setting of a known HIV infection, they produce a characteristic neuropathologic signature. The pathological findings are typically mild, even in cases where dementia is severe. Further, encephalitis is neither necessary nor sufficient for dementia. Thus, although the two frequently coexist, each may be present independent of the other. Immunocytochemical staining using antibodies directed against the HIV envelope protein gp41 are helpful in delineating the extent of brain infection. Some degree of neuronal loss can be demonstrated, but this correlates only modestly with cognitive status. Instead, severe damage to dendrites and synapses is readily evident. The sparsity of infected cells and the imprecise correlation between the language disturbance are absent. Patients are not able to learn new information, such as word lists, as well as previously, but they do not show the rapid forgetting that is commonly seen in Alzheimer's disease. Also affected are patients' abilities to maintain and shift attention and to sustain a line of reasoning to solve a problem. These features are characteristic of executive cognitive dysfunction [73-76].

Simple staging scales, such as the Memorial Sloan Kettering AIDS Dementia Complex Scale, may be used to characterize the severity of dementia. In advanced stages of HIV dementia, now rarely seen, patients are apathetic, indifferent and may be confined to bed due to motor impairment and incontinence. The neurological examination will show frontal release signs, spasticity and hyperreflexia, particularly in the legs. Prior to the advent of potent, combination antiretroviral therapies, HIV dementia was often progressive and carried a poor prognosis; the median survival was six months. With ART, however, patients stabilize or improve and may survive for many years if virological control is maintained.

Diagnosis. The diagnoses of HIV dementia and milder cognitive impairment are made by clinical criteria, after exclusion of other potential causes. No single laboratory test establishes the diagnosis, but ancillary studies are useful for

Table 2. HIV dementia diagnostic criteria

Seropositivity to HIV (confirmed by Western-blot)

History of progressive alterations in cognition and behavior Demonstrated impairment in at least two domains of neuropsychological performance

Absence of

Focal signs on neurological examination

Intoxication or withdrawal (alcohol or other substance)

Metabolic disturbance

CNS opportunistic infection or neoplastic lesions

severity of pathology and the degree of dementia indicates that host factors are likely to play a role in neuropathogenesis. Alterations in the balance of cytokines, neurotrophic factors, and neurotoxins, including glutamate receptor active compounds, have been found. An important unanswered question is why some patients with HIV infection develop dementia before death while others do not.

Clinical features and course. HIV-associated dementia should be suspected when a patient presents with insidiously progressive cognitive decline occurring over a period of weeks or months. The classical triad is cognitive, behavior and motor symptoms (Table 2). In early stages, the neurological examination is typically normal or shows only slowing of repetitive movements or increased tendon reflexes. Focal cortical signs such as hemianopsia, agnosia, or paraphasic 
Table 3. Clinical signs and symptoms of HIV dementia

\begin{tabular}{|c|c|c|}
\hline & Symptoms & Signs \\
\hline \multirow[t]{2}{*}{ Cognitive } & Poor Concentration & Slowness of thought \\
\hline & Forgetfulness & $\begin{array}{l}\text { Executive cognitive } \\
\text { dysfunction }\end{array}$ \\
\hline \multirow[t]{2}{*}{ Motor } & Gait instability & $\begin{array}{l}\text { Saccadic ocular pursuit } \\
\text { movements }\end{array}$ \\
\hline & $\begin{array}{l}\text { Urinary urgency/ } \\
\text { hesitation }\end{array}$ & $\begin{array}{l}\text { Slowing of repetitive } \\
\text { movements }\end{array}$ \\
\hline Behavior & $\begin{array}{l}\text { Loss of interest in } \\
\text { friends, hobbies }\end{array}$ & Apathy \\
\hline
\end{tabular}

supporting or refuting it. [24,77-79]. Table 3 lists clinical diagnostic criteria [77,80]. Neuropsychological evaluation is particularly helpful in cases where impairment is mild or moderate.

Differential diagnostic considerations. The principal differential diagnostic considerations in HIV patients with cognitive changes are encephalopathies (delirium) due to drugs and metabolic derangements, chronic brain syndromes, due to substance use and head injury, CNS opportunistic disease and severe primary psychiatric disturbances. Renal and hepatic insufficiency are capable of causing encephalopathy directly, or through diminished clearance of CNS-active drugs. In toxic and metabolic encephalopathies, delirium with variable attention and arousal represents the most typical presentation. Occasionally, however, chronic use of medications, such as narcotic analgesics, anticholinergics, and antipsychotics, can result in an insidious cognitive deterioration that may mimic dementia. An attempt should be made to remove or reduce the dose of any potentially offending agents [24,67,81,82].

Useful tests. When available, neuropsychological testing is very helpful in diagnosis (Table 4) [83,84]. It provides clear documentation of cognitive impairment, and it assists in differentiating HIV dementia from other disorders that may cause impairment. Useful screening NP tests for HIVD are those that examine psychomotor speed, such as the Trailmaking Tests, Grooved Pegboard and Digit-Symbol [32]. Also useful are tests of verbal and nonverbal learning (e.g., the Hopkins Verbal Learning Test) and sustained attention (Paced Auditory Serial Addition Test). Such tests should be administered by an experienced examiner, and interpreted by comparison to normative data with appropriate demographic corrections, including age, gender, education, and in some cases, ethnicity. The influence of premorbid conditions, including previous head trauma, learning disability, as well as the effects of systemic illness and substance abuse need to be considered carefully when interpreting results from NP testing.

Molecular markers, such as Beta2-microglobulin, quinolinic acid, and neopterin in CSF are not sufficiently
Table 4. Neurocognitive disruption diagnosis

\begin{tabular}{ll}
\hline $\begin{array}{l}\text { Intellectual pre morbid } \\
\text { estimated function }\end{array}$ & WRAT-3 Reading \\
Speed of information processing & WAIS III Digit symbol \\
& WAIS III Symbol search \\
& WAIS III Processing \\
Trail Making test part A & Stroop Color and Word test \\
Speed index & Hopkins verbal learning \\
Learning and memory & test-revised \\
& Brief visuospatial memory \\
& test-revised
\end{tabular}

Abstraction/executive functioning Category test

Wisconsin card sorting

test (version 64 items)

Trail making test part B

Stroop Color and Word test

Verbal fluency

Letter fluency

Category fluency (animals)

Attention/working memory sequencing

WAIS III letter number

Paced auditory serial

addition task

Motor

Grooved Pegboard test, dominant and nondominant hands

Humor

Beck depression inventory

sensitive or specific to assist in clinical diagnosis. Some immunological activation markers, such as neopterin, Beta2 microglobulin, quinolonic acid, PGE2, and PAF, studied in CSF, could help in the diagnosis, mainly neopterin and Beta-2 microglobulin, although they are not used routinely.

Treatment. The question is whether ARV therapy is beneficial in preventing and treating HIV neurocognitive disorders, and in particular, whether some drugs or combinations thereof are better than others. A substantial literature has accumulated in this area, and numerous different approaches to answering these questions have been taken. Despite the size of the literature, and the degree of interest in the question, no randomized clinical trials have directly compared the effectiveness for treating dementia of one HAART regimen to another. This is because viral load reduction and prevention of HIV disease progression (immune deficiency, opportunistic disease) has taken primacy over all else in the treatment of HIV to date.

Multiple lines of evidence substantiate the impression that HAART has benefited many patients with HIV-associated neurocognitive disorders, and that it may have delayed or prevented such disorders in others. It is not possible to 
Table 5. Penetration of antiretroviral drugs into cerebrospinal fluid and drug concentrations in comparison to HIV inhibitory concentrations (concentrations are in $\mathrm{mmol} / \mathrm{l})$ [85]

\begin{tabular}{|c|c|c|c|c|c|c|c|c|}
\hline \multirow[b]{2}{*}{ Drug } & \multirow[b]{2}{*}{$\begin{array}{l}\text { Molecular } \\
\text { weight kD }\end{array}$} & \multirow[b]{2}{*}{$\begin{array}{c}\text { Protein } \\
\text { binding }(\%)\end{array}$} & \multicolumn{3}{|c|}{ ARV concentrations } & \multicolumn{3}{|c|}{ CSF/CI50 } \\
\hline & & & Plasma* & CSF & $\begin{array}{l}\text { Virologic } \\
\text { IC50 }\end{array}$ & Low & High & Median \\
\hline \multicolumn{9}{|l|}{ NRTIs } \\
\hline Zidovudine & 267 & $34-38$ & $4.49-6.74$ & $0.12-0.41$ & $0.01-0.04$ & 3.00 & 41.00 & 22.00 \\
\hline Abacavir & 404 & 49 & $5.20-10.89$ & $0.50-1.83$ & $0.24-1.49$ & 0.34 & 7.60 & 4.00 \\
\hline Lamivudine & 229 & $<36$ & $4.37-8.74$ & $0.05-1.14$ & $0.78-4.90$ & 0.01 & 1.50 & 0.74 \\
\hline Stavudine & 224 & 'Negligible' & $3.35-6.43$ & $0.20-0.36$ & $0.34-2.12$ & 0.09 & 1.10 & 0.58 \\
\hline Didanosine & 236 & $<5$ & $2.12-11.00$ & $0.17-0.51$ & $2.53-15.84$ & 0.01 & 0.20 & 0.11 \\
\hline Zalcitabine & 211 & $<4$ & $0.05-0.18$ & $0.003-0.03$ & $0.19-1.22$ & 0.00 & 0.16 & 0.08 \\
\hline \multicolumn{9}{|l|}{ nNRTIs } \\
\hline Nevirapine & 266 & 60 & $7.52-16.92$ & $1.30-10.90$ & $0.02-0.14$ & 8.90 & 474.00 & 241.00 \\
\hline Delavirdine & 516 & 98 & $15.00-55.00$ & $0.02-0.22$ & $0.0006-0.0036$ & 5.60 & 367.00 & 186.00 \\
\hline Efavirenz & 316 & 99.5 & $9.20-16.60$ & $0.006-0.09$ & $0.008-0.052$ & 0.12 & 11.00 & 5.70 \\
\hline \multicolumn{9}{|l|}{ PIs } \\
\hline Indinavir & 712 & 60 & $12.20-13.00$ & $0.03-0.66$ & $0.0031-0.0195$ & 1.50 & 213.00 & 108 \\
\hline Amprenavir & 506 & 90 & $10.60-19.20$ & BDL-0.36 & $0.0046-0.0289$ & 0 & 78.00 & 39.00 \\
\hline Nelfinavir & 568 & $>99$ & $5.63-8.45$ & BDL-0.012 & $0.0014-0.0088$ & 0 & 8.60 & 4.30 \\
\hline Saquinavir & 767 & 98 & $1.85-3.23$ & BDL -0.008 & $0.001-0.006$ & 0 & 8.00 & 4.00 \\
\hline Ritonavir & 721 & 98-99 & $10.50-26.00$ & BDL-0.32 & $0.0049-0.0308$ & 0 & 6.50 & 3.30 \\
\hline Lopinavir & 629 & 98-99 & $8.30-22.30$ & NA & $0.0019-0.0475$ & - & - & - \\
\hline
\end{tabular}

BDL, Barely detectable; NA, not available.

recommend a specific antiretroviral regimen and there is no specific treatment for HIV-associated dementia (HAD).

One small, multicenter controlled clinical trial directly evaluated the efficacy of antiretroviral monotherapy for HIVassociated dementia. Zidovudine given orally in doses of 1000 to $2000 \mathrm{mg} /$ day was found to be superior to a placebo with respect to changes in performance in a composite neuropsychological battery of tests. The test battery comprised measures of timed gait, speeded movements, and psychomotor performance. Learning, memory, problem-solving skills, and visuospatial function were not assessed. The doses of zidovudine employed were significantly higher than those in routine use today (500 to $600 \mathrm{mg} /$ day).

In 1998, a reverse transcriptase inhibitor, abacavir, was tested in a placebo-controlled, double-blinded study of 99 patients with HAD. Abacavir had been shown to have good CSF penetration and was active in macrophages, HIV's principal target cell within the brain. During the planning phases of this study, rapid changes in ARV treatment patterns were occurring. Subjects were randomized to add $600 \mathrm{mg}$ abacavir BID, or a placebo, onto stable background ARV (PIbased HAART in approximately $50 \%$ of the cases). Participants in the trial were highly ARV-experienced; resistance mutations were present in $90 \%$ of these subjects at study entry. Modest and similar degrees of improvement in neuropsychological performance were observed in both the abacavir and placebo groups. Deterioration in the ADC stage during the 12 weeks of the study occurred in only two subjects, both of who were in the placebo group. The CSF virological response favored abacavir, with a $0.64 \log$ drop during the study, while the placebo group showed a drop of only $0.26 \mathrm{log}$. Changes in cognitive function and in the ADC stage were not related to declines in CSF HIV RNA. Rapid changes in ARV treatment patterns occurred while this study was being planned and carried out. These changes were motivated by an improved understanding of factors leading to the development of drug resistance. Today, clinicians typically change multiple ARV medications at once, maximizing selection pressures on multiple viral genes, and thereby rendering it difficult for HIV to acquire effective resistance through mutation. In retrospect, adding a single agent to an existing regimen would not now be considered an effective ARV treatment strategy.

Nevertheless, some general recommendations for individualized therapy can be made with confidence. First, patients with HIV neurocognitive disorders should be evaluated with respect to virus control. If they are candidates for a change in antiretroviral therapy based on an elevated plasma HIV RNA level ( $>400$ copies/mL on two or more consecutive occasions), then a new regimen should be proposed, following current treatment guidelines, which are evolving rapidly. The regimen should include at least two new agents, and it should avoid drugs to which the patient has a history of prior significant exposure, since the patient may already possess resistance to these drugs. Resistance genotyping and phenotyping assays may provide additional guidance in planning a new regimen that is likely to be 
efficacious. Concomitant medications and supplements must be reviewed, since drug interactions are common. All protease inhibitors are substrates and inhibitors of the hepatic cytochrome p450 enzyme system.

The NNRTIs also are metabolized through the CYP3A pathway, leading to significant drug interactions with PIs. Additional considerations in selecting specific agents should include the convenience of the dosing regimen (e.g., QD or BID dosing is better than TID or QID dosing), and expected CNS drug penetration (more is better). Zidovudine, abacavir, indinavir and nevirapine appear to be useful alternatives to include in a combination regimen for patients with dementia, based upon their pharmacokinetic properties, tolerability, likely CNS penetration and convenience.

Penetration of antiretroviral drugs into cerebrospinal fluid, and drug concentrations in comparison to HIV inhibitory concentrations are shown in Table 5 [85].

The effect on neuropsychological function of ARV drugs that are able to penetrate into the brain in effective concentrations remains unclear. A study found no direct benefit of neuroactive HAART therapy in patients with advanced HIV infection [86]. However, in neuropsychologically impaired patients, there was a benefit in memory function. This suggests that a threshold of neuropsychological impairment is required for the benefit of neuroactive HAART.

A study to evaluate whether CSF drug penetration and CSF virological suppression influence neuropsychological improvement during ART had shown that subjects on regimens containing a greater number of CSF-penetrating drugs had a significantly greater reduction in CSF viral load. Subjects attaining CSF virological suppression demonstrated greater global deficit score improvement than those who did not [87].

There are some papers showing that in spite of bad penetration of ARVs in CNS, if there is improvement of the systemic disease and viral load or CD4 there is improvement and reduction in HAD incidence.

Neuroprotective therapy. Because cognitive impairment and dementia may persist even in patients whose viral load is undetectable, clinical trials have begun to evaluate the effectiveness of neuroprotective therapies. This approach to treatment of dementia uses agents that inhibit the production of various endogenous neurotoxins believed to be important mediators of neural injury, such as glutamate, cytokines and reactive oxygen species. Examples include memantine, which blocks NMDA glutamate channels, CPI-1189, which acts as an anti-oxidant and protects from injury mediated by the cytokine, TNF-alpha, and selegiline, or deprenyl, which is an anti-oxidant and selective MAO-B inhibitor. Although promising, to date there are no conclusive results recommending these for routine use.

Vacuolar myelopathy related to HIV. Vacuolar myelopathy occurs in $10 \%$ of all patients with AIDS. It is clinically characterized by spastic paraparesis without a defined sensitivity level, proprioception impairment, and higher impairment of vibratory than painful sensitivity [77]. This condition is pathologically characterized by vacuolar degeneration of the spinal cord. It affects the thoracic level more frequently than the cervical level of the spinal cord, which in turn is more affected than the lumbar level. The lateral column is more frequently affected than the posterior columns. Some authors question if HIV is related to vacuolar myelopathy, because similar conditions are found in immuno-compromised patients without HIV [24, 88].

\section{Conclusions}

There are a vast number of unanswered questions regarding the relationship between HIV infection and the central nervous system. At this point in time, the vaccine or cure to this grave illness is beyond the horizon. We do, however, have a clear picture of the progression of the pandemic and of ongoing studies involving continually changing treatment regimens, giving those who are currently at the mercy of HIV and AIDS a longer, better life.

\section{References}

1. Szwarcwald C.L., Bastos F.I., Esteves M.A.P., Andrade C.L.T.A. Disseminação da epidemia de aids no Brasil, no período de 1987-1996: uma análise espacial. Cadernos de Saúde Publica 2000;16(suppl 1):7-19.

2. Ribeiro C.E.L. Impacto da aids na mortalidade de mulheres no município de Curitiba [M.Sc. thesis]. Curitiba (PR): UFPR, 2001.

3. Soto Ramirez L.E. Physiopathology and treatment of acquired immunodeficiency syndrome. Rev Invest Clin 2000; $52: 60-71$.

4. Power C., McArthur J.C., Johson R.T., et al. Demented and nondemented patients with AIDS differ in brain-derived human immunodeficiency virus type 1 envelope sequences. Journal of Virology 1994;68:4643-9.

5. Alaeus A. Significance of HIV-1 genetic subtypes. Scandinavian Journal of Infectious Disease 2000;32:455-63.

6. Cahn P., Belloso W.H., Murillo J., Prada-Trujillo G. AIDS in Latin America. Infectious Disease Clinics of North America 2000; $14: 185-209$.

7. Antunes C.C., Cecchni F.M., Bolli F.B., et al. Cerebral trypanosomiasis and AIDS. Arquivos de Neuropsiquiatria 2002;60:730-3.

8. Cohen J.E., Tsai E.C., Ginsberg H.J., Godes J. Pseudotumoral chagasic meningoencephalitis as the first manifestation of acquired immunodeficiency syndrome. Surgical Neurology 1998;49:324-7.

9. Di Lorenzo G.A., Pagano M.A., Taraturo A.L., et al. Chagasic granulomatous encephalitis in immunosuppressed patients. Computed tomography and magnetic resonance imaging findings. Journal of Neuroimaging 1996;6:94-7.

10. Gallo P., Fabiao Neto O.M., et al. Acute central nervous system infection by Trypanosoma cruzi and AIDS. Arq Neuropsiquiatr 1992;50:375-7. 
11. Gluckstein D., Ciferri F., Ruskin J. Chaga's disease: another cause of cerebral mass in the acquired immunodeficiency syndrome. American Journal of Medicine 1992; 92:429-32.

12. Lazo J., Meneses A.C., Rocha A., et al. Chagasic meningoencephalitis in the immunodeficient. Arquivos de Neuropsiquiatria 1998;56:93-7.

13. Lazo J., Meneses A.C., Rocha A., et al. Toxoplasmic and chagasic meningoencephalitis in patients with human immunodeficiency virus infection: anatomopathologic and tomographic differential diagnosis. Revista da Sociedade Brasileira de Medicina Tropical 1998;31:163-71.

14. Lages-Silva E., Ramirez L.E., Silva Vergara M.L., Chiari E. Chagasic meningoencephalitis in a patient with acquired immunodeficiency syndrome: diagnosis, follow up, and genetic characterization of Trypanosoma cruzi. Clinical Infectious Disease 2002;34:118-23.

15. Pagano M.A., Segura M.J., Di Lorenzo G.A., et al. Cerebral tumor-like american trypanosomiasis in acquired immunodeficiency syndrome. Annals of Neurology 1999; 45:403-6.

16. Pimentel P.C., Handfas B.W. Carmignani M. Trypanosoma cruzi meningoencephalitis in AIDS mimicking cerebral metastases: case report. Arquivos de Neuropsiquiatria 1996;54:102-6.

17. Rosemberg S., Chaves C.J., Higuchi M.L., et al. Fatal meningoencephalitis caused by reactivation of Trypanosoma cruzi infection in a patient with AIDS. Neurology 1992;42:640-2.

18. Silva N., O’Bryan L., Medeiros E., et al. Trypanosoma cruzi meningoencephalitis in HIV-infected patients. Journal of AIDS and Hum Retrovirology 1999;20:342-9.

19. Bernard G., Duarte A.J. Paracoccidiodomycosis: a model for evaluation of the effects of human immunodeficiency virus infections on the natural history of endemic tropical diseases. Clinical Infectious Diseases 2000;31:1032-9.

20. Finamor L.P., Muccioli C., Martins M.C., et al. Ocular and central nervous system paracoccidioidomycosis in a pregnant woman with AIDS. American Journal of Ophtalmology 2002; 134: 456-9.

21. Navia B.A., Jordan B.D., Price R.W. The AIDS dementia complex: I clinical features. Annals of Neurology 1986; 19:517-24.

22. Petito C.K., Cho E.S., Lemann W., et al. Neuropathology of acquired immunodeficiency syndrome (AIDS): an autopsy review. Journal of Neuropathology and Experimental Neurology 1986:45;635-46.

23. Vitkovic L., Tardieu M. Neuropathogenesis of HIV-1 infection. Outstanding questions. C R Acad Sci III 1998;321:1015-21.

24. Berger J.R., Levy R.M. Editors. AIDS \& the nervous system.Philadelphia: Lippincott - Raven, 2 ed; 1997.

25. Brew B.J., Pemberton L., Cunninghan P., Law M.G. Levels of human immunodeficiency virus type 1 RNA in cerebrospinal fluid correlate with AIDS dementia stage. Journal of Infectious Diseases 1997; 175:963-6.

26. Gendelman H.E., Lipton S.A., Epstein L., Swindells S. Editors (1998). The neurology of AIDS. New York: Chapman \& Hall, 1998.

27. Ho D.D., Byington R.E., Schooley R.T., et al. Isolation of HTLVIII from cerebrospinal fluid and neural tissues of patients with neurologic syndromes related to the acquired immunodeficiency syndrome. New England Journal of Medicine 1985;313:1493-7.
28. Resnick L., DiMarzo-Veronese F., Tourtellotte W.W., et al. Intrablood-brain-barrier synthesis of HTLV-III specific IgG in patients with neurologic symptons associated with AIDS or AIDS-related complex. New England Journal of Medicine 1985;313:1498-504.

29. Gonda M.A., Wong S.F., Gallo R.C., et al. Sequence homology and morphologic similarity of HTLV-III and Visna virus, a pathogenic Lentivirus. Science 1985;227:173-7.

30. Marshall D.W., Brey R.L., Cahill W.T., et al. Spectrum of cerebrospinal fluid in various stages of human immunodeficiency virus infection. Archives of Neurology 1988;45:954-8.

31. Resnick L., Berger J.R., Shapshak P., Tourtellotte W.W. Early penetration of the blood brain barrier by HIV. Neurology 1988;38:9-14.

32. Evans K.E., Donley D.K., Whitaker J.N. Neurological manifestations of infection with the Human Immunodeficiency viruses. In: Scheld WM, Whitley RJ, Durack DT. Infections of the Cetral Nervous System. New York: Raven Press; 1991, p 201-32.

33. Carne C.A., Tedder R.S., Smith A., et al. Acute encephalopathy coincident with seroconversion for anti- HTLV-III. Lancet 1985; 2 :1206-8.

34. Fishman R.A. Cerebrospinal fluid in diseases of the nervous system. 2ed. Philadelphia. W.B. Saunders, 1992.

35. McArthur J.C. Neurologic manifestations of AIDS. Medicine 1987;66:407-37.

36. Price R.W. The two faces of HIV infection of cerebrospinal fluid. Trends in Microbiology 2000;8:387-90.

37. Brew B.J., Wesselingh S.L., Gonzales M., et al. How HIV leads to neurological disease. MJA 1996;164:233-4.

38. Cross A.K., Woodroofe M.N. Chemokine modulation of matrix metalloproteinases and TIMP production in adult rat brain microglia and a human microglial cell line in vitro. Glia 1999;28:183-9.

39. Paul R., Lorenzl S., Koedel U., et al. Matrix metalloproteinases contribute to the blood-brain barrier disruption during bacterial meningitis. Annals of Neurology 1998;44:592-600.

40. Stingele K., Haas J., Zimmermann T., et al. Independent HIV replication in paired CSF and blood viral isolates during antiretroviral therapy. Neurology 2001;56:355-61.

41. Wong J.K., Günthard H.F., Ellis R.J., et al. The development and trafficking of multi-drug resistant HIV in plasma and CSF during the failure of combination antiviral therapy. Antiviral Therapy 1999; (1):76-7.

42. Bajetto A., Bonavia R., Barbero S., et al. Chemokines and their receptors in the central nervous system. Front Neuroendocrinol 2001;22:147-84.

43. Bajetto A., Bonavia R., Barbero S., Schettini G. Characterization of chemokines and their receptors in the central nervous system: physiopathological implications. Journal of Neurochemistry 2002;82:1311-29.

44. Biber K., Zuurman M.W., Dijkstra I.M., Boddeke H.W. Chemokines in the brain: neuroimmunology and beyond. Current Opinion in Pharmacology 2002;2:63-8.

45. Gabuzda D., He J., Ohagen A., Vallat A.V. Chemokine receptors in HIV-1 infection of the central nervous system. Seminars in Immunology 1998;10:203-13.

46. Hicks A., Potula R., Sui Y.J., et al. Neuropathogenesis of lentiviral infection in macaques: roles of CXCR4 and CCR5 viruses and interleukin-4 in enhancing monocyte chemoattractant protein-1 production in macrophages. American Journal of Pathology 2002;161:813-22. 
47. Corasaniti M.T., Bagetta G., Rotiroti D., Nisticò G. The HIV envelope protein gp 120 in the nervous system: interactions with nitric oxide, interleukin-1BETA and nerve growth factor signaling, with pathological implications in vivo and in vitro. Biochemistry Phamacol 1998;56: $153-6$.

48. Dawson T.M., Dawson V.L. Gp 120 neurotoxicity in primary cortical cultures. Advances in Neuroimmunology 1994;4; 167-73.

49. Tyler K.L., McArthur J.C. Through a glass, darkly: cerebrospinal fluid viral load measurements and the pathogenesis of human immunodeficiency virus infection of the central nervous system. Archives of Neurology 2002;59:909-12.

50. Karpus W.J. Chemokines and central nervous system disorders. Journal of Neurovirology 2001; 7:493-500.

51. Kaul M., Lipton S.A. Chemokines and activated macrophages in HIV gp120-induced neuronal apoptosis. Proceedings of the National Academy of Sciences of the United States of America 1999;96:8212-6.

52. Letendre S.L., Lanier E.R., McCutchan J.A. Cerebrospinal fluid beta chemokine concentrations in neurocognitively impaired individuals infected with human immunodeficiency virus type 1. Journal of Infectious Diseases 1999;180:310-9.

53. Glass J.D., Wesslingh S.L. Viral load in HIV-associated dementia. Annals of Neurology 1998;44:150-1.

54. Nath A. Pathobiology of human immunodeficiency virus dementia. Seminnars of Neurology 1999;19:113-27.

55. Patel C.A., Mukhtar M., Pomerantz R.J. Human immunodeficiency virus type $1 \mathrm{Vpr}$ induces apoptosis in human neuronal cells. Journal of Virology 2000; 74:9717-26.

56. Power C., Kong P.A., Crawford T.O., et al. Cerebral white matter changes in Acquired immunodeficiency syndrome dementia: alterations of the blood brain barrier. Annals of Neurology 1993;34:339-50.

57. Petito C.K. Neuropathology of human immunodeficiency virus: questions and answers. Human Pathology 1996:27;623-4.

58. Torres-Munoz J.E., Redondo M., Czeisler C., et al. Upregulation of glial clustering in brains of patients with AIDS. Brain Research 2001;888:297-301.

59. Dore G.J., Correll P.K., Li Y., Kaldor J.M., et al. Changes to AIDS dementia complex in the era of highly active antiretroviral therapy. AIDS 1999; 13:1249-53.

60. Abbott N.J. Glia and the blood-brain barrier. Nature 1987;325:195.

61. Dana Consortium on therapy for HIV dementia and related cognitive disorders. Clinical confirmation of the American Academy of Neurology algorithm for HIV-1 associated cognitive/motor disorder. Neurology 1996;47:1247-53.

62. McClernon D.R., Lanier R., Gartner S., et al. HIV in the brain: RNA levels and patterns of zidovudine resistance. Neurology 2001;57:1396-401.

63. Tambussi G., Gori A., Capiluppi B., et al. Neurological symptoms during primary human immunodeficiency virus (HIV) infection correlate with high levels of HIV RNA in cerebrospinal fluid. Clinical Infectious Diseases 2000;30:962-5.

64. Ellis R.J., Hsia K., Spector S.A., et al. Cerebrospinal fluid human immunodeficiency virus type 1 RNA levels are elevated in neurocognitively impaired individuals with acquired immunodeficiency syndrome. HIV Neurobehavioral Research Center Group. Annals of Neurology 1997;42:679-88.
65. Ellis R.J., Moore D.J., Childers M.E., et al. Progression to neuropsychological impairment in Human immunodeficiency virus infection predicted by elevated cerebrospinal fluid levels of Human Immunodeficiency virus RNA. Archives of Neurology 2002;59:923-8.

66. Zink M.C., Clements J.E. The two faces of HIV infection of cerebrospinal fluid: response. Trends in Microbiology 2000;8:390-1.

67. McArthur J.C., Hoover D.R., Bacellar M.A., et al. Dementia in AIDS patients: incidence and risk factors. Neurology 1993; $43: 2245-52$.

68. Portegies P., de Gans J., Lange J.M., et al. Declining incidence of AIDS dementia complex after introduction of zidovudine treatment. British Medical Journal 1989:299;819-21.

69. Graham N.M., Hoover D.R., Park L.P., et al. Survival in HIVinfected patients who have received zidovudine: comparison of combination therapy with sequential monotherapy and continued zidovudine monotherapy. Multicenter AIDS Cohort Study Group. Annals of Internal Medicine 1996; $124: 1031-8$.

70. Dore G.J., Cooper D.A., Pozniak A.L., et al. Eficacy of Tenofovir Disoproxil Fumarate in antiretroviral therapy naïve and experienced patients coinfected with HIV-1 and Hepatitis B Virus. Journal of Infectious Diseases 2004; 189:1185-92.

71. Sacktor N.C., Lyles R.H., Skolasky R.L., et al. Combination antiretroviral therapy improves psychomotor speed performance in HIV-seropositive homossexual men. Multicenter AIDS Cohort Study (MACS). Neurology 1999;52:1640-7.

72. Maschke M., Kastrup O., Esser S., et al. Incidence and prevalence of neurological disorders associated with HIV since the introduction of highly active antiretroviral therapy (HAART). Journal of Neurology, Neurosurgery and Psychiatry 2000;69:376-80.

73. Clifford D.B. AIDS dementia. Medical Clinics of North America 2002;86:537-50.

74. Gartner S. HIV infection and dementia. Science 2000;287:6024.

75. Levy J.A., Hollander H., Shimabukuro J., Mills J. Isolation of DIDS associated retroviruses from cerebrospinal fluid and brain of patients with neurological symptoms. Lancet 1985; $14: 586-8$.

76. Major E.O., Rausch D., Marra C., Clifford D. HIV- associated dementia. Science 2000;288:440-1.

77. Harrison M.J.G. Guidelines for management of HIV associated dementia, myelopathy, neuropathy and myopathy. Internal Journal of STD \& AIDS 1998;9:390-3.

78. Polich J., Ilan A., Poceta J.S., et al. Neuroelectric assessment of HIV: EEG, ERP and viral load. Internal Journal of Psychophysiology 2000;38:97-108.

79. Power C., Selnes O.A., Grim J.A., McArthur J.C. HIV dementia scale: a rapid screening test. Journal of AIDS and Hum Retrovirology 1995;8:273-8.

80. Brew J.B., Dunbar N., Pemberton L., Kaldor J. Predictive markers of AIDS dementia complex: CD4 cell count and cerebrospinal fluid concentrations of $\mathrm{B}_{2}$ microglobulina and neopterin. Journal of Infectious Diseases 1996; 174 : 294-8.

81. McArthur J.C. NeuroAIDS: diagnosis and management. Hosp Pract 1997;15:73-97. 
82. Schifitto G., Kieburtz K., McDermott M.P., et al. Clinical trials in HIV-associated cognitive impairment: cognitive and functional outcomes. Neurology 2001;56:415-8.

83. Butters N., Grant I., Haxby J., et al. Assessment of AIDSrelated cognitive changes: recommendations of the NIMH Workshop on Neuropsychological Assessment Approaches. Journal of Clinical and Experimental Neuropsychology 1990; $12: 963-78$.

84. Heaton R.K., Grant I., Butters N., et al. The HNRC 500 neuropsychology of HIV infection at different disease stages. HIV Neurobehavioral Research Center. Journal of the International Neuropsychological Society 1995; $1: 231-51$.
85. McCutchan J.A., Letendre S. Pharmacology of antiretroviral drugs in the central nervous system: pharmacokinetics, antiretroviral resistance, and pharmacodynamics. In Neurology of AIDS, Second Edition. Gendelman H., Grant I., Everall I., Lipton S., and Swindells S. (eds.). Oxford University Press, 2005.

86. Lucette A.J., Cysique M.A., Maruff P., Brew J.B. Antiretroviral therapy in HIV infection: are neurologically active drugs important? Arch Neurol 2004;61:1699-704.

87. Letendre S.L., McCutchan J.A., Childers M.E., et al. Enhancing antiretroviral therapy for human immunodeficiency virus cognitive disorders. Ann Neurol 2004;56:416-23.

88. Tan S.V., Guiloff R.J. Hypothesis on the pathogenesis of vacuolar myelopathy, dementia, and peripheral neuropathy in AIDS. Journal of Neurology, Neurosurgery and Psychiatry 1998;65:23-8. 